\title{
BREAKING BAD IN MISSISSIPPI: DO COUNTY-LEVEL ALCOHOL SALE BANS ENCOURAGE CRYSTAL METHAMPHETAMINE PRODUCTION AND CONSUMPTION?
}

\author{
GRANGER Maury \\ College of Business, Jackson State University, USA \\ PRICE Gregory \\ Department of Economics, Morehouse College, USA
}

\begin{abstract}
:
If alcohol has substitutes, changes in its relative price can encourage the production and consumption of other illicit and harmful drugs. This paper considers if county-level bans on the sale of alcohol in the state of Mississippi encourage the production and consumption of crystal methamphetamine. We estimate the parameters of a drug production function in which the inputs are the density of people and firms, underscoring the importance of learning and knowledge spillovers to production and consumption. Poisson and Negative Binomial parameter estimates reveal that county-level bans on hard liquor sales; but not on beer and wine, increase the number of crystal methamphetamine labs. In the absence of such laws, there would be approximately 308 fewer crystal methamphetamine labs in the state of Mississippi. Our findings suggest that in Mississippi, which is the least healthiest state in the nation, county-level bans on hard liquor sales are not welfare improving as they encourage substitution for a drug that is potentially more harmful to individual health than alcohol.
\end{abstract}

Key words: Alcohol Prohibition, Substitution Effects, Crystal Methamphetamine Production.

\section{Introduction}

If alcohol has substitutes, changes in its relative price can encourage the production and consumption of other drugs-both legal and illegal (Cameron and Williams, 2001; Dinardo and Lemieux, 2001; Fogarty, 2006; Olmstead et.al; 2015). There is some evidence that crystal methamphetamine is a substitute for alcohol, as Fernandez, Gohmann, and Pinkston (2015) and Harris (2015) find that in counties where the sale of alcohol is banned, the production of crystal methamphetamine as evidenced by the number clandestine lab seizures by the US Drug Enforcement 
Administration, is higher. This suggests that county-level alcohol prohibition laws, by increasing the relative price of alcohol, induces the production of crystal methamphetamine, as individuals demand it as a substitute for alcohol.

This paper considers if county-level bans on the sale of alcohol in the state of Mississippi encourage the production and consumption of crystal methamphetamine. Utilizing data on the number of crystal methamphetamine lab seizures in Mississippi from the United States Drug Enforcement Administration, we estimate the parameters of a drug production function in which the inputs are the density of people and firms, underscoring the importance of learning and knowledge spillovers to production and consumption. Given that Mississippi is the least healthiest state in the country (United Health Foundation, 2014), our inquiry will inform the extent to which county-level bans on the sale of alcohol contribute to poor individual health. Relative to alcohol, and perhaps other illicit drugs, crystal methamphetamine use by individuals is associated with far more severe and expensive individual health outcomes (Marshall, and Werb, 2010; Shrem and Halkitis, 2008). In this context, our results will cast insight into whether or not county-level alcohol prohibition laws are welfare improving, and serves the public health interest in Mississippi.

Our inquiry makes at least two contributions. First, we contribute to the literature on the economics of prohibition (Miron and Zwiebel, 1995), and the possible adverse consequences of it (Conlin, Dickert-Conlin, and Pepper, 2001). In our our theoretical and empirical framework, county-level bans on alcohol sales increase the relative price of producing and consuming alcohol, possibly inducing substitution for crystal methamphetamine. Given that improving the health of individuals and enforcing laws against illicit drug use is costly, our inquiry also contributes to the literature on the economics of harm reduction (Baumann and Friehe, 2014; Cameron and Collins, 2006; Stevenson, 1994). In particular, our analysis will inform the extent to which alcohol prohibition laws condition the adverse health effects associated with crystal methamphetamine use (Dobkin and Nicosia, 2009) in Mississippi-a state that is the least healthiest in the nation (United Health Foundation, 2014).

The remainder of this paper is organized as follows. In the second section we provide a theoretical framework for the production of crystal methamphetamine. We appeal to how production and productivity scales to measures of firm and people density in geographic space, which enables a parsimonious specification of a production function specification for crystal methamphetamine at the county-level. The third section discusses the data and empirical methodology. As our dependent variable — crystal methamphetamine lab seizures—constitute count data, we utilize Poisson and Negative Binomial specifications of a cross-county crystal methamphetamine production function. In the fourth section, we report and discuss parameter estimates. The last section concludes.

\section{Agglomeration, Density and Crystal Methamphetamine Production}

To theoretically motivate our empirical framework for estimating the effects of county- 
level alcohol prohibition on crystal methamphetamine production, we appeal to the evidence that production in general scales in general to measures of density that reflect the importance of learning and knowledge spillovers in transforming inputs into output. We posit that the production of crystal methamphetamine is also situated within an agglomeration economy. In an agglomeration economy (Puga, 2010), producers and consumer benefit from the density of ideas, infrastructure, firms, human capital that enable an efficient transformation of inputs into output. Firms are able to draw from a supply of labor with particular skills (Combes and Duranton, 2006), enhancing labor productivity through learning spillovers, and benefit from the quicker spread of ideas among firms within the same geographical cluster-or knowledge spillovers (Malecki, 2010) - that enhance the productivity of capital and labor inputs.

Given that agglomeration economies cause productivity to scale to firm and people density (Lobo et.al; 2013), similar to Abel, Dey and Gabe (2012) we assume that for the ith county, the crystal methamphetamine production is determined by:

$$
Y_{i}=A_{i} K_{i}^{\alpha} L_{i}^{1-\alpha}
$$

where $A_{i}$ is a Hicks-neutral technology parameter, $K_{i}$ is the stock of capital, and $L_{i}$ is the stock of labor. It is assumed that agglomeration effects at the county level are determined by $A_{i}=a_{o} D_{i 1}^{\gamma_{1}}$, and $L_{i}=b_{o} D_{i 2}^{\gamma_{2}}$, where $D_{i 1}^{\gamma_{1}}$ and $D_{i 2}^{\gamma_{2}}$ are measures of density that determine agglomeration effects for technology and labor respectively. The parameters $a_{o}$ and $b_{o}$ capture other constant factors that are independent of density, and $\gamma_{1}$ and $\gamma_{2}$ are the respective output elasticities.

As measuring the capital stock at a regional level such as a county are typically either unavailable, or subject to significant measurement bias, it is assumed that the cost of capital $-r_{k}$-is constant. The capital demand implied from the first-order condition for the marginal product of capital in (1) can then be substituted back in the production function to yield:

$$
Y_{i}=\left[a_{0} D_{i 1}^{\gamma_{1}}\left(b_{o} D_{i 2}^{\gamma_{2}}\right)^{1-\alpha}\left(\alpha / r_{k}\right)\right]^{1 / 1-\alpha}
$$

where for $\alpha<1, \partial Y_{i} / \partial D_{i 1} \geq 0$ if $a_{o} \geq 0, \gamma_{1} \geq 0$, and $\partial Y_{i} / \partial D_{i 2} \geq 0$ if $b_{o} \geq$ $0, \gamma_{2} \geq 0$.

The production function in (2) enables a specification for producing crystal methamphetamine at the county-level that is a function of measures of density that are characteristic of agglomeration economies. It presumes that like most marketed goods/services, the production of crystal methamphetamine benefits from the learning and knowledge spillovers associated with the density of people and firms in a 
geographic space. In equilibrium the supply of crystal methamphetamine, determined by $Y_{i}$, equals demand, and changes in demand induced by a change in the relative price of a substitute can change $Y_{i}$. Below, we exploit this to determine if $Y_{i}$ responds to county-level bans on alcohol consistent with alcohol and crystal methamphetamine being substitutes, as alcohol bans constitute an increase in the relative price of alcohol.

\section{Data and Empirical Methodology}

As a measure of county-level crystal methamphetamine production in Mississippi, we utilize data on the number of crystal methamphetamine lab seizures in Mississippi from the United States Drug Enforcement Administration (DEA), which identifies the county of lab location-accessed on 10/3/15 at http://www.dea.gov/clan-lab/clan-lab.shtml. While lab seizures are not measures of actual crystal methamphetamine production, it is plausible, and we assume that actual production is directly proportional to DEA lab seizures.

We utilize U.S Census Bureau data to construct two measures of density for the 82 counties in Mississippi: Persons Per Square Mile and Nonfarm Private Establishments Per Square Mile, all accessed on 10/3/15 at http://quickfacts.census.gov/qfd/states/28/28003.html . For the production function in (2) we posit that Nonfarm Private Establishments Per Square Mile is a relevant measure of $D_{i 1}$, and Persons Per Square Mile is relevant measure of $D_{i 2}$. In particular, we assume that firm density engenders knowledge and learning spillovers that enhance the productivity of both capital and labor, and the density of people engenders the knowledge and learning spillovers that enhance the productivity of labor.

Four Binary variables measuring alcohol sale bans were constructed from data reported by the Department of Revenue, State of Mississippi accessed on 10/3/15 at https://www.dor.ms.gov/abc/abc wet-drymap.html. The binary variables constructed measure if: 1.) The County Bans Hard Liquor Sales, 2.) The County Bans Hard Liquor Sales with Some Exceptions, 3.) The County Bans Beer \& Wine Sales, and 4.) The County Bans Beer \& Wine Sales with Some Exceptions. Each of these variables can be viewed as two treatments that increase the relative price of alcohol and beer \& wine.

Any specification of the production function in (2) augmented with dummy variables for alcohol prohibition could be misspecified for several reasons, resulting in biased parameter estimates. The implementation of alcohol prohibition laws could be endogenous, and there could be other unobservables that are correlated with measures of density. To control for this, we construct an amenity variable, which is the residual from an Ordinary Least Squares Regression of Median Value of Owner Occupied Housing on Median Household Income, and the Percent of Individuals white Race Only. The amenity variable, considered initially by Glaeser, Kolko and Saiz 
(2001), represents all the unobservables that determine why individuals are in a particular geography, reflecting a spatial equilibrium in which all relevant amenities are capitalized into housing prices (Granger and Price, 2014).

We add the percent of whites in a county to the OLS amenity regression, as relative to blacks, there is evidence that whites are more likely to use crystal methamphetamine (McCabe et.al, 2007), which could condition the unobservables relevant for the production of crystal methamphetamine. Given that the amenity variable represents unobservables relevant for the production of crystal methamphetamine, and for the existence of alcohol prohibition laws in a county, including it in a specification for (2) will mitigate and/or eliminate any bias associated with unobservables and endogeneity. As the dependent variable - the number of crystal methamphetamine lab seizures-is integer-valued, our parameter estimates are based on Poisson and Negative Binomial count data estimator regression specifications, in which the number of lab seizures is the regressand, and the density measures and amenity variable are regressors. Suppose $C_{i}$, the number crystal methamphetamine lab seizures in county $i$ is distributed as a Poisson or Negative Binomial (Cameron and Trivedi, 1998) random variable with mean $\lambda_{i}$, a count data estimator regression specification is based on:

$$
\ln \lambda_{i}=\beta^{\prime} \Omega
$$

where $\beta$ is a coefficient vector, and $\Omega$ is a vector of exogenous variables that determine the expected value of the number of crystal methamphetamine lab seizures $(\lambda)$ in the $i$ th county.

\section{Results}

A covariate summary for the regressand and regressors is reported in Table 1. Poisson and Negative Binomial parameter estimates are reported in Tables 2 and 3 . The estimates in Table 1 are without the amenity variable, whereas the estimates in Table 2 include the amenity variable. The parameter estimates report specifications for county-level bans on alcohol and for beer \& wine separately. For all Poisson parameter estimates, a chi-square test for mean-variance equality-a restriction of the Poisson regression specifications-is reported. As a Goodness-of-Fit measure, the Cragg and Uhler (1970) pseudo- $\mathrm{R}^{2}$ is reported for each estimated specification. To estimate the practical impact of county-level alcohol prohibition laws-for both hard alcohol and beer \& wine-we also report on the marginal effects of such laws on the average number of crystal methamphetamine laboratory seizures. The marginal effects estimates inform how crystal methamphetamine production and consumption in Mississippi responds to laws that ban the the sale of alcohol, and beer \& wine, at the county level.

The parameter estimates reported in Table 2 suggest that a Poisson regression 
specification is too restrictive, as for both alcohol and beer \& wine sale bans, the mean-variance restriction is rejected-justifying a Negative Binomial regression specification. In this instance, it appears that only county-level bans on the sale of alcohol, and not beer \& wine, have a positive and significant effect on the production of crystal methamphetamine. This is consistent with a county-level sales ban on alcohol increasing its relative price, and inducing substitution toward crystal methamphetamine. The marginal effect estimates suggest that if county-level bans on the sale of alcohol were removed, there would be approximately 352 fewer crystal methamphetamine labs in the state of Mississippi, estimated from cross-multiplying the estimated marginal effect-which measures the effect of the alcohol ban on the mean number of crystal methamphetamine lab seizures $(\lambda)$-and the number of counties in the sample.

The estimated sign and significance on the density parameters are also instructive. The density of population has a positive and significant effect on crystal methamphetamine production. The positive and significant effect of density of people suggests that knowledge and learning spillovers that enhance the productivity of labor, are relevant for the production and consumption of crystal methamphetamine. While the density of firms has a positive and significant in the Poisson specifications, it has a negative but insignificant effect in the preferred Negative Binomial specifications. This suggests that, at least for the production of crystal methamphetamine production and consumption in the state of Mississippi, firm density does not engender knowledge and learning spillovers that enhance the productivity of both capital and labor, or perhaps the effects offset to have a net effect of zero.

Given the possibility of endogeneity in the establishment of county-level prohibition laws, or other unobservables that determine the production of crystal methamphetamine production, the parameter estimates reported in Table 3 include the amenity variable as a regressor. The results are similar to those reported in Table 2 without the amenity regressor. The only change is in the marginal effect of alcohol prohibition on the number of crystal methamphetamine labs in the state of Mississippi. If county-level bans on the sale of alcohol were removed, there would be approximately 308 fewer crystal methamphetamine labs in the state of Mississippi.

\section{Conclusion}

Appealing to the idea that an illicit drug such as crystal amphetamine is a substitute for alcohol, this paper considered if county-level alcohol prohibition laws in Mississippi induce higher levels of crystal methamphetamine production. We estimated count data specifications of a county-level crystal amphetamine production function. Parameter estimates suggest that consistent with alcohol and crystal methamphetamine being substitutes, county-level alcohol bans in Mississippi appear to increase the relative price of alcohol, causing the production and consumption of crystal methamphetamine to increase. Whereas the infamous character Walter White in the American Move 
Classics iconic Breaking Bad series becomes a crystal methamphetamine criminal entrepreneur out of financial necessity, our results suggest that in the real world, extant public policy-county-level alcohol bans-enables this type of criminal entrepreneurship.

Our results suggest that eliminating county-level alcohol bans in the state of Mississippi would result in approximately 308 fewer crystal methamphetamine labs. Given that Mississippi is the least healthiest state in the nation (United Health Foundation, 2014), our findings suggest that existing county-level alcohol sales bans do not improve individual welfare. As such, one possible strategy for improving the health of Mississippians would be the elimination of county-level bans on the sale of alcohol. Such a policy would be consistent with optimal harm reduction, as crystal methamphetamine is an illicit drug that is potentially more harmful than alcohol (Gonzales, Mooney and Rawson, 2010).

Table 1

Covariate Summary

\section{Variable}

Number of Crystal

Methamphetamine

Lab Seizures:

- $2011^{a}$

Persons Per

Square Mile In

County: $2010^{b}$

Private Nonfarm

Establishments per

Square Mile

In County $2013^{b}$

County Bans

Hard Liquor Sales

$(\text { Binary }=1=\text { Yes })^{c}$

County Bans

Hard Liquor Sales

With Some Exceptions

$(\text { Binary }=1=\text { Yes })^{c}$

County Bans

Beer \& Wine Sales

$(\text { Binary }=1=\text { Yes })^{C}$

County Bans

Beer \& Wine Sales

With Some Exceptions
Standard

Deviation

9.95

62.24

64.03
Number of

Observations

82

82

82

82

82

82

82 
$(\text { Binary }=1=\text { Yes })^{c}$

Amenity

.00006

14775.37

82

Residual

Median

34636.35

7539.39

82

Household Income:

$-2013^{b}$

Median Value of

84992.68

28266.15

82

Owner Occupied:

Housing $2009-2013^{b}$

Percent of Individuals

.565

.202

82

White Race Only

In County $2014^{b}$

Source:

${ }^{a}$ US Drug Enforcement National Administration (DEA) Clandestine Laboratory Register at http://www.dea.gov/clan-lab/clan-lab.shtml

${ }^{b}$ US Census Bureau State and County Quick Facts at http://quickfacts.census.gov/qfd/states/28/28003.html

${ }^{c}$ Department of Revenue, State of Mississippi at https://www.dor.ms.gov/abc/abc_wet-drymap.html

Table 2

Poisson \& Negative Binomial Parameter Estimates

Crystal Methamphetamine Production and County Level Alcohol Prohibition in Mississippi

Specification :

Regressand: Number

of DEA Crystal

Methamphetamine

Lab Seizures In

County: 2004 - 2011

Regressors:

Constant

1.178

$(.0790)^{a}$

.0071

$(.0012)^{a}$

In County

Private Nonfarm

Establishments per

Square Mile

In County

County Bans

.5921

.1119

$(.0567)^{b}$

$-.5324$

(.3351)

$(.2096)^{a}$

.0251

$(.0081)^{a}$

0012)

$.0741)^{a}$

.8702

Hard Liquor Sales

County Bans

$(.1110)^{a}$

.0520

(.1109)

Hard Liquor Sales
.1164
$(.0563)^{b}$
.5920

$(.2473)^{b}$

$-.1298$

(.3318)
Poisson

Negative Binomial 
With Some

Exceptions

County Bans

.4269

.4785

Beer \& Wine Sales

$(.1131)^{a}$

(.2993)

County Bans

-.1561

$-.1467$

Beer \& Wine Sales

(.1213)

With Some

Exceptions

\section{Marginal Effect of \\ Alcohol Prohibition \\ On Production of \\ Crystal \\ Methamphetamine}

4.724

4.344

3.475

0

Number of

82

82

82

82

Observations

$\mathrm{H}_{o}: \alpha=0$

$387.68^{a}$

$426.30^{a}$

$\chi^{2}(1)$

Pseudo- $R_{c u}^{2}$

.999

.492

.999

.471

Notes: Standard errors are in parentheses.

aSignificant at the .01 level.

${ }^{b}$ Significant at the .05 level.

${ }^{c}$ Significant at the 10 level.

Pseudo- $R_{c u}^{2}$ is that of Cragg and Uhler (1970), and measures the likelihood ratio of an unrestricted model to a restricted constant only model. The less (more) likely the unrestricted regression specification is, the smaller (larger) is Pseudo- $R_{c u}^{2}$, and it is bounded between zero and unity. Total population and median income are log-transformed. The overdispersion test is a chi-square test for $\alpha=0$ in the Poisson meanvariance restriction $\operatorname{Var}(\lambda \mid \Omega)=\mathrm{E}(\lambda \mid \Omega)+\alpha^{2} \mathrm{E}(\lambda \mid \Omega)$.

Table 3

Poisson \& Negative Binomial Parameter Estimates

Crystal Methamphetamine Production and County Level Alcohol Prohibition in Mississippi
Specification :
Poisson
Negative Binomial
Poisson
Negative Binomial

Regressand: Number

of DEA Crystal

Methamphetamine

Lab Seizures In

County: 2004 - 2011 
Regressors:

Constant

Persons Per

Square Mile

In County

Private Nonfarm

Establishments per

Square Mile

In County

County Bans

Hard Liquor Sales

County Bans

Hard Liquor Sales

With Some

Exceptions

County Bans

Beer \& Wine Sales

County Bans

Beer \& Wine Sales

With Some

Exceptions

Amenity

Residual

Marginal Effect of

Alcohol Prohibition

On Production of

Crystal

Methamphetamine

Number of

82

$-.000006$

$(.000003)^{b}$

4.323

3.329

3.761
.2398
$(.0614)^{a}$

$-.3959$

(.3581)

.8181

$(.2095)^{a}$

.0233

$(.0086)^{b}$

(.3409)

.4675

$(.2537)^{b}$

-.0914

(.3252)
$-.00001$

$-.00001$

$-.00001$

$(.1143)^{a}$

(.2903)

$-.1582$

$-.1301$

(.1214)

(.3167)

Observations

$\mathrm{H}_{o}: \alpha=0$

$386.13^{a}$

$\chi^{2}(1)$

Pseudo- $R_{c u}^{2}$

.999

.513

.999

.504 
Notes: Standard errors are in parentheses.

${ }^{a}$ Significant at the .01 level.

${ }^{b}$ Significant at the .05 level.

${ }^{c}$ Significant at the .10 level.

Pseudo- $R_{c u}^{2}$ is that of Cragg and Uhler (1970), and measures the likelihood ratio of an unrestricted model to a restricted constant only model. The less (more) likely the unrestricted regression specification is, the smaller (larger) is Pseudo- $R_{c u}^{2}$, and it is bounded between zero and unity. Total population and median income are log-transformed. The overdispersion test is a chi-square test for $\alpha=0$ in the Poisson meanvariance restriction $\operatorname{Var}(\lambda \mid \Omega)=\mathrm{E}(\lambda \mid \Omega)+\alpha^{2} \mathrm{E}(\lambda \mid \Omega)$. The Amenity Residual is an Ordinary Least Squares residual from a regression of the Median Value of Owner Occupied Housing on Median Household Income and the Percent of Individuals White Race Only.

\section{References}

Abel, Jaison R., Ishita Dey, and Todd M. Gabe. 2012. "Productivity and the Density of Human Capital," Journal of Regional Science, 52: pp. 562 - 586.

Baumann, Florian, and Tim Friehe. 2014. "Regulating Harmless Activity to Fight Crime," Journal of Economics, 113: pp. 79 - 95.

Cameron, Samuel, and Alan Collins. 2006. "Addict Death: A Lacuna in the Welfare Economics of Drug Policy," American Journal of Economics and Sociology, 65: pp. 963 - 969.

Cameron, A. Colin and Pravin K. Trivedi. 1998. Regression Analysis of Count Data, Cambridge University Press, Cambridge, UK.

Cameron, Lisa., and Jenny Williams. 2001. "Cannabis, Alcohol and Cigarettes: Substitutes or Complements?" Economic Record, 77: pp. 19 - 34.

Combes, Pierre-Philippe, and Gilles Duranton. 2006. "Labour pooling, Labour Poaching, and Spatial Clustering," Regional Science and Urban Economics, 36: pp. 1 - 28.

Conlin, Michael., Stacy Dickert-Conlin, and John Pepper. 2001. "The Effect of Alcohol Prohibition on Illicit-Drug-Related Crimes." Journal of Law and Economics, 48: pp. 215 - 234.

Cragg, John G., and Russell S. Uhler. 1970. "The Demand for Automobiles," Canadian Journal of Economics, 3: pp. 386 - 406.

DiNardo, John, and Thomas Lemieux. 2001. "Alcohol, Marijuana, and American Youth: The Unintended Consequences of Government Regulation," Journal of Health Economics, 6: pp. $991-1010$.

Dobkin, Carlos, and Nancy Nicosia. 2009. "The War on Drugs: Methamphetamine, Public Health, and Crime," American Economic Review, 99: pp. 324 - 349.

Fernandez, Jose M., Stephan Gohmann, and Joshua C. Pinkston. 2015. Breaking Bad: Are Meth Labs Justified in Dry Counties?" Social Science Research Network, (August, 2015) http://ssrn.com/abstract=2650484.

Fogarty, James. 2006. "The Nature of the Demand for Alcohol: Understanding Elasticity," British Food Journal, 108: pp. 316 - 332.

Glaeser, Edward L., Jed Kolko, and Albert Saiz. 2001. "Consumer City," Journal of Economic Geography, 1: pp. 27 - 50.

Gonzales, Rachel., Larissa Mooney, and Richard Rawson. 2010. "The Methamphetamine Problem in the United States," Annual Review of Public Health, 31: pp. 385 - 398.

Granger, Maury and Gregory N. Price. 2014. "Are States with Larger than Average Black Populations Really the Worst Places to Live in the USA? A Spatial Equilibrium 
Approach to Ranking Quality of Life," Journal of Public Management and Social Policy, 20: Article 3.

Harris, Shannon. 2015. "High and Dry: An Economic Analysis of Drug Use in Dry Counties," Economics Undergraduate Honors Theses, Paper 13, University of Arkansas.

Lobo, Jose, Luis M.A. Bettencourt, Deborah Strumsky, and Geoffrey B. West. 2013. "Urban Scaling and the Production Function for Cities," PloS One 8: e58407.

Malecki, Edward J. 2010. "Everywhere? The Geography of Knowledge," Journal of Regional Science, 50: pp. 493 - 513.

Marshall, Brandon D.L., and Daniel Werb. 2010. "Health Outcomes Associated with Methamphetamine Use Among Young People: A Systematic Review," Addiction, 105: pp. 991 - 1002.

McCabe, Sean Esteban., Michele Morale.s, James A. Cranford., Jorge Delva., Melnee D. McPherson., and Carol J. Boyd. 2007. "Race/Ethnicity and Gender Differences in Drug Use and Abuse among College Students," Journal of Ethnicity in Substance Abuse, 6: pp. 75 - 95.

Miron, Jeffrey A., and Jeffrey Zwiebel. 1995. "The Economic Case Against Drug Prohibition," Journal of Economic Perspectives, 9: pp. 175 - 192.

Olmstead, Todd A., Sheila M. Alessi, Brendan Kline, Rosalie Liccardo Pacula, and Nancy M. Petry. 2015. "The Price Elasticity of Demand for Heroin: Matched Longitudinal and Experimental Evidence," Journal of Health Economics 41: pp. 59 - 71.

Puga, Diego. 2010. "The Magnitude and Causes of Agglomeration Economies," Journal of Regional Science 50: pp. 203 - 219.

Shrem, Michael T., and Perry N. Halkitis. 2008. "Methamphetamine Abuse in the United States Contextual, Psychological and Sociological Considerations," Journal of Health Psychology 13: pp. 669 - 679.

Stevenson, Richard. 1994. "Harm Reduction, Rational Addiction, and the Optimal Prescribing of Illegal Drugs," Contemporary Economic Policy 12: pp. 101 - 108.

United Health Foundation. 2014. America's Health Rankings: A Call To Action for Individuals and Their Communities, 25th Anniversary Edition, United Health Foundation Minnetonka MN. 